and so man can, for the present, continue his slave trade without any qualms of conscience.

The exhibition arranged by the North-West Branch of the Institution of Electronics and held at the College of Technology, Manchester, during July 22-23, might justly be described as a tour of the torture chambers of the electrons, the scale of tortures being finely graded from the mere interchange of habitat, as in accumulators, to the dragging out into free space and violent oscillation that occurs in highfrequency valves. In fact, this gradation provides a convenient basis for the classification of the various items that were shown in the exhibition.

The Chloride Electrical Storage Company exhibited many examples of accumulators and an interesting set of illustrations of rather unusual uses. These were happily chosen to cover a wide field-from the upper atmosphere (in radio-sonde apparatus) to below sea-level (the detection of fire-damp in mines). And to hint at more drastic electronic exercises, a portable oscilloscope was shown.

The various types of discharge lamps might well form the next subject. In these, electrons are caused to collide with the molecules of a rarified gas, which is thereby ionized; the return to the stable state is manifested by the emission of light, and, so far, this method of producing light is the most economical of power. It has, however, other advantages : it can be made almost instantaneous, by discharging a condenser through the lamp; and it can be used for stroboscopic purposes, by causing the discharge to occur periodically. Siemens showed examples of photographs taken with their 'Sieflash' argon lamp, which can produce an intensity of more than $10^{8}$ lumens in a single flash lasting $10^{-4}$ sec. Ferranti's showed examples of their neon-filled 'Neostron', which is particularly designed for stroboscopic purposes.

The next stage of complication may well be taken as the radio valve; many examples were shown by Mullard's, Ferranti's, Cossor's and B.T.H. Particularly outstanding were the Mullard water-cooled $20 \mathrm{~kW}$. valve and their valves made of silica, the internal construction of which was shown by sectioned models.

In addition to making electrons oscillate, we can subject them to lateral forces; this leads us to the cathode ray oscillograph-that 'maid-of-all-work' of the modern laboratory. Numerous examples of the utility of this instrument were shown, ranging from the visual observation of the electrical changes that occur in heart-beats (the Cossor electrocardiograph) to the vibration analyser of G.E.C. and Mullard. Many standard models were also shown by various firms, with suggestions for the different ways in which they can be utilized. Of particular interest were the small G.E.C. Miniscope and the Ferranti exhibit showing electron diffraction by an internally mounted specimen of zine oxide.

Although interest was mainly centred on electrons, some space was also devoted to the means whereby electron convolutions are made possible-that is, the production of high vacua. Metropolitan-Vickers showed models of their pumps and pressure gauges, and a sectional model of a demountable $\mathrm{X}$-ray tube in which these are used. Edwards also showed examples of modern pumps and the various oils used in them. People who use high-vacuum equipment are perhaps apt to take this side of their apparatus for granted, and these two stands should have helped to impress on such people that vacuum production is still a skilled art, and that improvements are continually being introduced in the process.

The range of application of all these devices was illustrated by many examples, and mention of only a few gives some idea of the uses to which electronics can be put in modern industry. There were a potentiometric titration apparatus, a layer-thickness meter for non-magnetic coatings on magnetic bases, a moisture-in-timber meter, controls to provide constant meter speed independent of load, dielectric heating for insulators or poor conductors, spot-welder control for accurate reproduction of welds, and clothguiding equipment for use in mills.

In short, one gained the impression that there was nothing that electrons cannot do, given the guiding hand of science behind them, and the exhibition fully served its purpose in directing attention to these powers. But largely it was preaching to the converted, and many looked with envy on the instruments that they could not purchase, or that they could only be promised months or years hence. If exhibitions such as this show us the golden age of the future, they also impress upon us the fact that it has not yet begun, and that a great deal of hard and concentrated work is necessary before we can usher it in.

\section{NO PEARLS IN COCO-NUTS}

$\mathrm{D}$ R. A. REYNE has recently published a detailed description of work carried out during the War "On the Structure of the Shells and Pearls of Tridacna squamosa Lam. and Hippopus hippopus (Linn.)" (Arch. néerl. Zool., 8, 206; 1947). The structures of the pearls and shells were studied by grinding surfaces in different directions, by examination of thin splinters, by slow solution in acids and by X-ray diffraction photographs. The author unfortunately lost his collection during enemy action at Wageningen in 1944 and 1945 , so that a thinsection study has still to be made, and in the absence of photographs of some pearls and sections he has supplied text-figures drawn from his notebook sketches.

The structure of the Tridacna shell is elaborated in greater detail than in O. B. Bøggild's "The Shell Structure of the Molluscs" (1930), and the author claims to have written the first description of the Hippopus shell. X-ray powder photographs of the shell and the pearls of the species described show that the chief inorganic component is aragonite. The orientation of the fibrous crystallites of aragonite revealed by a photograph of a chatoyant pearl has not, however, been studied in detail.

Dr. Reyne was chief of the Coco-nut Research Station at Menado (Celebes) 1930-33 and examined the collection of "Coco-nut pearls" of the late Dr. J. G. F. Riedel, who claimed to have found one in a coco-nut which he opened himself (Nature, 115,138 ; 1925). Dr. Reyne concludes that these are all true Tridacna pearls and that Riedel had been deceived by some trick of the natives. Even in 1835 Quoy and Gaimard were already of the same opinion, who writing of Tridacna said "c'est aussi le lieu de parler de ces perles assez grosses, mais peu régulières, que secrète le manteau, et qui, dans plusiers endroits de l'Inde, aux Moluques et aux Mariannes, passent pour être un produit de la végétation, et se trouver dans l'intérieur de la noix de coco". 